\title{
Research on Engineering Cost Management Based on Big Data and BIM
}

\author{
Yetao Pang, Xiaoman Zheng \\ Chongqing Real Estate College, China
}

Keywords: big data; BIM; engineering cost management

\begin{abstract}
This paper elaborates engineering cost management from the perspective of big data and BIM. Firstly, it analyzes the factors affecting the engineering cost management level and the problems existing in engineering cost management. At the same time, it expounds the application of big data and BIM in engineering cost management, and proposes specific measures, so as to provide reference for engineering construction enterprises to carry out engineering cost management work.
\end{abstract}

\section{Introduction}

The project cost is to clarify, manage and control the cost of the whole process of the infrastructure project, analyze the budget of the construction unit, rationally plan the flow of funds, constrain the over budget funds, effectively improve the utilization of funds, maximize profits and avoid waste of resources. And cost control. Under the new situation of "counting pricing”, the standard environment for ensuring the development of construction industry cost, stricter management of the whole process cost, and further strengthening the application and management capacity of new technologies [1].

BIM technology is one of the emerging building technologies in recent years. Its core is the construction of building information model. It promotes the innovation of engineering cost in the construction industry through 3D modeling and 3D computing. It is characterized by visualization, coordination, sharing and simulation. In the development of enterprises, data and talents are equally important to the competitive development of enterprises. The arrival of the era of big data provides a new data processing method such as data cloud computing, which provides convenient conditions for data collection, storage and utilization. As one of the construction industry projects directly related to data assets, project cost needs to pay more attention to the use of big data, and realize data sharing through scientific and standardized methods to maximize the value of data.

\section{Project cost big data}

\subsection{The meaning of engineering cost big data.}

The so-called project cost data is a collection of information, including information about the internal and external environment of the project construction enterprise and the project cost. Under normal circumstances, the characteristics of engineering cost data are mainly represented by the massive data, heterogeneous multi-source, dynamic and so on. For the project cost data, its content mainly involves the cost data of the project level, enterprise level, enterprise group level, and enterprise ecological level. Among them, the project-level cost data mainly includes the cost data related to the target project and the cost data formed by the project.

\subsection{The characteristics of engineering cost big data.}

1) Collect data in a multi-agent, multi-level manner. The transmission of engineering cost data collection needs to analyze the single market structure and enterprise engineering operations, and then rationalize the construction projects of different levels, and finally apply them to the engineering construction through multi-level audit of the project cost. Although this method can effectively guarantee the accuracy of data calculation, and also meets the rigorous standards of engineering cost calculation, the efficiency is relatively low, and there is still some error in the processing of details. At this stage of the big data engineering cost analysis and calculation of the data through the establishment of a permanent database, without taking into account the market structure issues. The 
use of big data computing and database simulation calculation to achieve the main control of the project cost project, the technology is not only more accurate, efficiency is effectively improved, but also more secure, it is not appropriate to generate data loss and core data theft and other related issues, Effectively improve the overall efficiency of project cost. 2) The selectivity of data updates. Compared with the acquisition of technical data, big data engineering has higher cost selectivity, can realize multi-angle simulation for various engineering constructions, effectively solve the complexity of project cost management project management, and further change market environment data and engineering construction. The data is mastered in real time, and detailed data simulation data is provided, which makes the selection of data information more comprehensive and the related work is more unified, enabling relevant technicians to effectively obtain and calculate engineering information through various channels.

\section{Characteristics of BIM Technology in Engineering Cost Management}

\subsection{BIM technology can display architectural drawings in a three-dimensional way.}

Architectural drawings are generally flat, and the different components in the construction project are generally displayed in a plane such as lines, so that for more complicated parts, the construction unit can only imagine according to the image, due to the lack of a more intuitive understanding. Therefore, it is inevitable that some deviations will occur due to inconspicuous imagination. However, the introduction of BIM technology has solved the above problems. The BIM technology changes the vector in the design drawing, and the two-dimensional plan is converted into a three-dimensional physical image, which can directly see the stereo image, so that the technical constructor does not need to try hard to imagine, and this also realizes different engineering.

\subsection{BIM technology provides a means for coordination between project contractors and owners.}

Engineering construction is a very large project involving multiple subjects. Therefore, there are often problems that need to be coordinated during the construction process. At this time, it is necessary to bring together the relevant subjects to discuss problems and find solutions. In fact, at this time, the project has already had problems, and the purpose of the collective discussion is to find a solution. After the introduction of BIM technology, the coordination service in BIM technology can be utilized to coordinate the possible problems in the early stage of construction, thus ensuring effective communication between related entities, and with the support of BIM technology, Refer to the coordinated data to develop a countermeasure.

\subsection{BIM technology enables full-scale simulation of drawings.}

BIM technology can realize the transformation of drawings from 2D to 3D. In addition, BIM technology can simulate the things that are not on the drawings. For example, the building will definitely involve the fire protection system, and the fire protection system is very complicated, through BIM technology. It is possible to simulate the lines of various fire protection systems and choose the most suitable one.

\subsection{BIM technology can display architectural drawings in a three-dimensional way.}

Architectural drawings are generally flat, and the different components in the construction project are generally displayed in a plane such as lines, so that for more complicated parts, the construction unit can only imagine according to the image, due to the lack of a more intuitive understanding. Therefore, it is inevitable that some deviations will occur due to inconspicuous imagination. However, the introduction of BIM technology has solved the above problems. The BIM technology changes the vector in the design drawing, and the two-dimensional plan is converted into a three-dimensional physical image, which can directly see the stereo image, so that the technical constructor does not need to try hard to imagine, and this also realizes different engineering. 


\section{Current status and problems of project cost management}

In China, due to the influence and constraints of the planned economic system, there are some problems in project cost management, which further restricts the effect of project cost management.

\subsection{Cost management is not closely linked to the market.}

At present, the engineering cost management mode commonly used by all walks of life in China is unified by the competent authorities of all regions to use the unit price method to prepare the project budget quota implementation price management (regional average cost price), and to adjust the market dynamic price in stages, and to guide the price and the specified price. In combination, the guiding coefficient is periodically announced from time to time, and then the project cost agency in each region prepares, reviews, and determines the project cost. With the development of the market economy, the limitations of the existing construction project cost management system and management model are becoming more and more obvious, and have begun to restrict the improvement and development of management level.

\subsection{The cost data update is not timely.}

We all know that design changes, visa claims are often abound on the engineering site and material price fluctuations are also very frequent. This requires us to make timely adjustments to the quantity and price of the project cost. The traditional method is to manually determine the position on the drawing and then calculate the increase or decrease of the amount caused by the design change. At the same time, you need to adjust the components associated with it. This process is not only slow, it takes a long time, and reliability is difficult to guarantee. In addition, there is no location information and historical data, and the query is very troublesome in the future. This is also the limitation of current cost management.

\subsection{Multiple pricing is difficult to do.}

The construction project has a long cycle, large scale and high cost. Therefore, the project cost should be carried out in stages according to the construction procedure, and multiple valuations should be carried out at the corresponding stage. To ensure the scientific determination of the project cost and control, although multiple pricing can ensure that the project cost level is gradually deepened, gradually refined and gradually approached the actual cost, it also brings a great burden to the project cost management work. In reality, many construction companies only pay attention to the project one end and two ends. The price is completely abandoned for the cost management in the process. Therefore, often after the project is completed, it is found that the actual cost is very different from the previous budget. At this time, it is too late to take action. For construction units, the phenomenon of budget overruns is also very common. The first is the inability to make accurate estimates; secondly, the lack of reliable cost data is also an important cause of cost overruns [2].

\section{The impact of BIM technology on engineering cost enterprises and employees under the background of big data era}

\subsection{The impact on the cost of the enterprise.}

A large part of the existing cost-making enterprises are enterprises that mainly rely on the employment of primary cost personnel. The application of BIM technology in the context of big data era requires cost-building enterprises to transform their technological content. Once the company attaches importance to technological innovation, it will certainly bring about the expansion of the company's scale, including more refined services, more small cost consulting companies, more detailed cost consulting market, and more emphasis on knowledge and technology as the core competitiveness of the company. Wait. Under the guidance of BIM technology, cost consulting companies can flexibly change their organizational structure according to market demand, use big data and BIM technology to timely explore customer needs, and pay attention to the cultivation of high-quality talents, thus continuously improve their competition. 


\subsection{The impact on the employees in the cost industry.}

According to the application problem of BIM technology reflected by current cost personnel, BIM technology has problems in the specific application of the difference between the participants of the project, the complexity of software tools, and the low level of big data processing. In the past, the structure of the employees in the cost industry was mainly based on cheap labor. After the implementation of BIM technology, the structure of the employees in the cost industry must be transformed into a capital-intensive industry dominated by capital strength, and then turned to technology-intensive, therefore, the cost industry the practitioners must constantly improve their professional quality and technical level.

\section{Research on the management method of engineering cost under big data and BIM}

\subsection{Focus on talent training.}

When BIM technology is further applied, the cost consulting industry has formed the characteristics of more and more distinct knowledge-intensive industries. As an important carrier of knowledge, talents are of great significance to the development of enterprises, and talents can provide a continuous source of power for enterprise development. Therefore, the new engineering cost consulting and management personnel should have knowledge of engineering, economics, management and law, and must have certain foreign language and computer operation capabilities. When selecting talents, enterprises should pay attention to the rich engineering practice experience and good professional ethics of the personnel. In daily business activities, it is necessary to increase and increase the proportion of personnel training activities, conduct centralized training of personnel, and do a good job in talent reserve and team. The construction of personnel echelons will lay a good talent foundation for the improvement of the overall level of the project cost industry.

\subsection{Solve information technology problems with BIM.}

With the development of economy and the advancement of science and technology, BIM has been widely used in engineering project construction enterprises to improve the engineering cost management level of enterprises. In the market, due to the wide variety of BIMs, or the engineering cost personnel are not skilled in their operation, and thus to a certain extent, the efficiency of project cost management is restricted. Based on this, when the project construction enterprise chooses BIM, it pays attention to the compatibility of BIM. On the one hand, it is easy to operate; on the other hand, it lays a foundation for transmitting engineering cost data. When using big data to process engineering cost information, it is necessary to analyze the information data processing technology, focusing on the maturity and practicability of the processing technology. After accumulating certain data processing experience, use more sophisticated technologies, such as clouds.

\subsection{Strengthen cooperation and purchase professional databases.}

When organizing the project cost management work, through the strengthening of cooperation and the purchase of professional databases, it fundamentally compensates for the lack of information source of the large project cost database. For the project cost information of the file specification class, as well as some external engineering cost information, etc., the corresponding information obtained under normal circumstances is relatively small. For engineering project construction enterprises, external information can be obtained by means of cooperation and purchase of professional engineering cost database. First, establish strategic alliances with enterprises in the same industry, share the project cost database, and enrich project cost data to a certain extent. Information source; Secondly, establish a cooperative relationship with professional engineering cost consulting institutions, supplement their own engineering cost information with their professional engineering cost data information; finally, in combination with the actual situation of the project objectives, the professional cost database can be purchased through commercialization. To some extent, it meets the needs of project cost management. 


\subsection{Implement the entire process of project cost control.}

The implementation of the whole process control of the project cost is conducive to the further application of BIM technology, and can effectively measure the application effect of BIM technology. BIM technology has evolved from the original 3D model to the 5D model. The scope of its management model has been continuously expanded, and all engineering information and business information such as construction organization plan and cost construction have been integrated, which is conducive to the management of project cost. In addition, the model established by BIM technology can include information of various professions, which is beneficial for designers, contractors and supervisors to conduct multi-angle audits of drawings on a unified platform, and can also perform 3D, 4D or even 5D of BIM technology. Simulated collision inspection, this visual simulation function of BIM technology provides great convenience for project cost management, can timely discover the cost and actual discrepancies, reduce rework, and avoid disputes to the greatest extent.

\subsection{Improve the construction of enterprise databases.}

In order to make enterprise engineering cost management and BIM technology better adapt, cost consulting enterprises should continuously improve the enterprise database. The established database should include cost index database, engineering case database, component information database and price information database, etc. It can provide strong support for centralized management and call model data, engineering quantity data, human machine price data, and quota consumption data at any time. In addition, the improvement of the database can also help the project in the early stage of decision-making to make empirical judgments, saving time, economic and labor costs to the greatest extent, and further supporting the efficient control of project cost.

\subsection{Education and training for engineering cost personnel.}

For engineering construction enterprises, it is necessary to provide education and training for engineering cost personnel and cultivate composite cost talents. Based on big data and BIM engineering cost management, on the one hand, engineering cost personnel have rich knowledge of cost management, and on the other hand, they have professional big data processing capabilities. However, in practice, engineering cost personnel rely heavily on technology to meet the needs of the development of composite talents. Based on this, firstly organize education and training activities to help cost management personnel to improve information processing capabilities; secondly, set up a project cost management team; finally, through the business outsourcing method, the cost data processing business will be handed over to professional institutions.

\section{Summary}

With the further deepening of big data application technology, the models that management enterprises need to manage and integrate in the actual operation process are more and more complex and complex. The engineering cost industry has proposed more visualization, real-time access and platform collaboration. Therefore, construction companies must pay attention to the application of BIM technology in engineering cost, and closely combine the characteristics of the era of big data to improve the adaptability of "Internet + BIM technology" to engineering cost.

\section{References}

[1] X.F. Xu and F.T. Zhou, on the transformation of BIM technology to promote cost management, Engineering Economics, 2014, vol.12, pp.6-9.

[2] D.T. Li, Exploration and Innovation of Engineering Cost in the BIM Era, Western china science and technology, 2015, vol.8, pp.73-75.

[3] Sh.Ch. Yan and Ch.L. Yin, Analysis of the impact and countermeasures of BIM on the construction cost industry in the era of big data, computer programming skills and maintenance, 2016, 
vol.8, pp.69-70.

[4] W.H. Fu, L.Y. Ma, Research on Engineering Cost Management Based on BIM Technology, Building technology, 2016, vol.7, pp.57-59.

[5] W.W. Zhao and Sh.W. Zeng, Application Research of BIM Technology in Data Management of Railway Signal Equipment, Railway standard design, 2017, vol.1, pp.12-14.

[6] X.F. Yin, Research on Construction Engineering Cost Management Based on BIM and IPD Collaborative Management Model, Dalian University of Technology, 2015, vol.5, pp.11-14.

[7] F.L. Li and J.T. Fang, Application and Benefit Analysis of BIM Technology in Engineering Cost Management, Value Engineering, 2016, vol.4, pp.32-35. 